\title{
Is Self-Efficacy Related to the Quality of Life in Elite Athletes after Spinal Cord Injury?
}

\author{
Agata Goraczko ${ }^{1,2}\left(\mathbb{D}\right.$, , Alina Zurek ${ }^{3}(\mathbb{D})$, Maciej Lachowicz ${ }^{1}$, Katarzyna Kujawa ${ }^{1,2}$ and Grzegorz Zurek ${ }^{1, *(D)}$ \\ 1 Department of Biostructure, Wroclaw University of Health and Sport Sciences, 51-612 Wroclaw, Poland; \\ agagoraczko@gmail.com (A.G.); maciej.lach93@gmail.com (M.L.); katarzyna.kujawa@awf.wroc.pl (K.K.) \\ 2 Clinic of Neurorehabilitation, 54-519 Wroclaw, Poland \\ 3 Institute of Psychology, University of Wroclaw, 50-527 Wroclaw, Poland; alina.zurek@uwr.edu.pl \\ * Correspondence: grzegorz.zurek@awf.wroc.pl; Tel.: +48-600-081-799
}

Citation: Goraczko, A.; Zurek, A.; Lachowicz, M.; Kujawa, K.; Zurek, G. Is Self-Efficacy Related to the Quality of Life in Elite Athletes after Spinal Cord Injury? Int. J. Environ. Res. Public Health 2021, 18, 10866. https:// doi.org/10.3390/ijerph182010866

Academic Editor: Joshua F. Yarrow

Received: 7 September 2021

Accepted: 14 October 2021

Published: 15 October 2021

Publisher's Note: MDPI stays neutral with regard to jurisdictional claims in published maps and institutional affiliations.

Copyright: (c) 2021 by the authors. Licensee MDPI, Basel, Switzerland. This article is an open access article distributed under the terms and conditions of the Creative Commons Attribution (CC BY) license (https:// creativecommons.org/licenses/by/ $4.0 /)$.

\begin{abstract}
Background: A spinal cord injury (SCI) is a traumatic event that affects every aspect of life: physical, mental, economic, and social. The main aim of this study was to investigate self-efficacy, quality of life, and their correlations among outstanding athletes who have suffered spinal cord injuries, and to determine whether these individuals have specific psychological characteristics that contribute to a better quality of life. Methods: The study involved nine athletes with at least national-level achievements in sports prior to an SCI. Participation in the study consisted of an interview via an online communicator, followed by an online questionnaire consisting of a personal questionnaire and two scales: The World Health Organization Quality of Life Scale (WHOQoL-BREF), and the General Self-Efficacy Scale (GSES). Results: Spearman's correlation showed a correlation between general self-efficacy, perception of quality of life, and satisfaction with own physical health, as well as psychological resources and environmental support. Conclusions: Involvement in an environment that was important to the injured person before the accident, in either a passive (in the absence of functional capacity) or active form, promotes a greater sense of self-efficacy and good QoL, regardless of the time that has passed since the accident, and despite high levels of pain or secondary health issues. To fill the gap in professional long-term healthcare services for athletes after SCIs, intervention programs should be considered that support self-efficacy, which is an important factor that can be subject to improvement.
\end{abstract}

Keywords: quality of life; self-efficacy; spinal cord injury; elite athletes; sport

\section{Introduction}

There is no question that spinal cord injury (SCI) is a traumatic experience causing a complete change in one's life. In terms of physical health, the injured person not only experiences limitations in sensory and motor functions, but also a range of other disorders related to the basic functions of the urinary, digestive, respiratory, and cardiovascular systems, as well as sexual activity, sleep, spasticity, and chronic pain [1-5]. Work activities are often disrupted, resulting in economic decline and social isolation [6]. There have been numerous studies on the consequences of SCIs - including psychological problems-and rehabilitation programs aimed at managing the effects of SCIs [7-12]. However, the benefits of these interventions are limited due to the extent of the challenges posed by SCIs, along with the associated social disadvantages and chronic pain [13,14]. De Roon-Cassini (2009) points out that what matters most is not the physical limitation of a person after their SCI, but how the impairment is perceived by the injured person [15]. Individuals who feel less impaired may report a greater sense of life and derive greater value from daily activities [16]. Quality of life (QoL) among people with SCIs depends not so much on factors related to disability (e.g., completeness of core injury, degree of motor impairment) as on factors that are modifiable by therapy, such as self-efficacy (S-E) [13]. The QoL scales, which present the judgment of people about their health life status in different domains, 
and S-E, which assesses one's belief about the ability to cope with a variety of difficult situations, are both largely subjective measures [17-20]. Hampton (2001) found that S-E was a very significant contributor to QoL when compared with disability variables and, irrespective of social support, people with higher levels of S-E appeared to be more satisfied with their lives than did people with low S-E [21,22]. Longitudinal studies suggest that S-E is a potential determinant of adjustment outcomes in the long term [23].

Ackery et al., (2007) indicate that the number of spinal cord injuries has been increasing in recent years, which may be due to the desire to perform increasingly extreme stunts and the level increase in competitive sports [24]. The study of Chan et al., (2016) identified six countries where sports account for more than $13 \%$ of SCIs (Russia, Fiji, New Zealand, Iceland, France, and Canada), as well as the highest risk sports of diving, skiing, rugby, and horseback riding $[25,26]$. Hockey, skiing, diving, and American football almost exclusively produce cervical SCI injuries, while more than half of the injuries in horseback riding and snowboarding are thoracic or lumbosacral injuries [25].

The main objective of this study was to investigate the correlation between S-E and QoL in a group of outstanding athletes who have experienced spinal cord injury while being active athletes, and to determine whether they have specific psychological resources that influence a better quality of life [27]. The results provide insight into the unique world of elite athletes, potentially contributing to a better understanding of whether such people with intrinsic personal attributes may show resilience related to SCIs [28].

\section{Materials and Methods}

Participation in the study consisted of an interview via an online communicator, followed by an online questionnaire consisting of a personal questionnaire and two scales: The World Health Organization Quality of Life Scale (WHOQoL-BREF), and the General Self-Efficacy Scale (GSES). Before the interview, all participants (P) read a consent form - which included the title and purpose of the study, explanation of its procedures, and confidentiality rules - and then gave informed verbal acceptance of the conditions presented (Please see the Supplementary Material). All interviews were conducted by the first author, who has years of experience both in clinical work with patients after SCIs and as their assistant. The interview was semi-structured, wherein the first part was conducted using the dialogue method, allowing the respondent to speak freely, while the second part included questions about motivation, goals in life, and social activities, among others. Each interview lasted approximately 1.5-2.5 h, was recorded and then transcribed, and its content was used to analyze the results. Consent to conduct the research project was obtained from the Senate Research Ethics Committee of the University School of Physical Education in Wroclaw, Poland (corresponding ethical approval code: 37/2018, art.27, Dz.U.1997, poz.553).

The following eligibility criteria were adopted for the study: sports achievements at the minimum national level (winning a medal at national competitions) before SCI, spinal cord injury (tetraplegia or paraplegia), and consent to participate in the study. An additional criterion was the knowledge of either the Polish or English language at a level allowing the respondent to communicate.

The personal questionnaire included questions about the participants' demographic aspects (gender, nationality, age, marital status), injury (circumstances of injury, level of spinal cord injury, level of pain experienced daily), and sport practiced (type, best sports performance, sports activity after SCI).

Pain experienced daily was assessed using the 0-10 Numerical Rating Scale of Pain ( $0=$ no pain, $10=$ most intense pain) .

Quality of Life was examined using the abbreviated version of the WHOQoL scale (WHOQoL-BREF). Adaptations of national scales were used. This scale is currently considered to be the most appropriate instrument for assessing the quality of life in people with SCIs $[29,30]$. Each item is described by a five-level Likert scale, where participants indicate satisfaction (5: strongly agree, 4: agree), neutrality (3: neither agree or disagree), or dissat- 
isfaction (2: disagree, 1: strongly disagree). The two first items are examined separately and inform the researcher about one's overall perception of one's quality of life and health satisfaction. For the first question (Q1) of the questionnaire: "How would you rate your QoL?", participants who answered "very poor", "poor" or "neither poor nor good" were classified as having a negative perception of QoL, while those who answered "good" or "very good" were classed as positive. The next 24 questions describe 4 domains: physical health (D1), psychological (D2), social (D3), and material aspect (D4) [31]. For the analysis of the WHOQoL-BREF results, the raw point values obtained for the individual domain were recalculated on a scoring scale ranging from 4 to 20, in line with the World Health Organization recommendations [32]. The results are scaled in a positive direction-the higher the score, the higher the respondent's quality of life in each domain [31].

The General Self-Efficacy Scale (GSES) is a 10-item psychometric scale that assesses optimistic self-beliefs to cope with a variety of difficult demands in life, as well as own ability. For example, item 1 is phrased: "I can always manage to solve difficult problems if I try hard enough". The scale was created by Matthias Jerusalem and Ralf Schwarzer in 1981 and has been widely used in numerous studies worldwide [19]. Each item is rated on a four-point scale, where $1=$ not at all true, and $4=$ exactly true. Responses to the 10 items are summed to produce a total score, ranging from 10 to 40 points, where a higher score indicates higher self-efficacy [33]. Unlike other scales that assess optimism, this one specifically addresses personal agency.

The study conducted was qualitative. In order to deepen the analysis, calculations were performed to extract common features and correlations. This was possible due to the homogeneity of the group of participants in terms of the adopted criteria. The mean and standard deviation were calculated separately for questions Q1, Q2, and the individual domains of WHOQoL-BREF, GSES, and pain. The correlation between domains of QoL and S-E, as well as their relationship with pain and the number of years since the injury, were examined using Spearman's rank correlation, with $p<0.05$ indicating statistically significant results. All calculations were performed using Statistica version 13.1 in the Biostructure Research Laboratory of Wroclaw University of Health and Sport Sciences (certificate ISO 9001).

\section{Results}

\subsection{Participants}

Figure 1 shows a flowchart of participants' inclusion in the study. After analyzing information about spinal cord injuries among prominent athletes, and selecting individuals who met the study criteria, an invitation to participate in the project was sent by e-mail to 32 athletes from 5 continents who had suffered spinal cord injuries, from the following countries: USA, UK, Canada, Brazil, Poland, Austria, Australia, Japan, and South Africa. Ultimately, nine participants from Europe and North America participated in the study.

Table 1 lists demographic and injury-specific information on the participants. The age of the participants ranged from 24 to 55 years. Participants were selected from among both tetraplegic and diplegic patients. All participants were successful, at a minimum, at a national level before the accident, with three participants being world champions and one a European champion. Three subjects did not participate in sports after their SCI, for two of whom this was due to the amount of damage and lack of functional capacity. After their accidents, six subjects participated in sports, competing in national and international competitions, and two of them became Paralympic champions. 


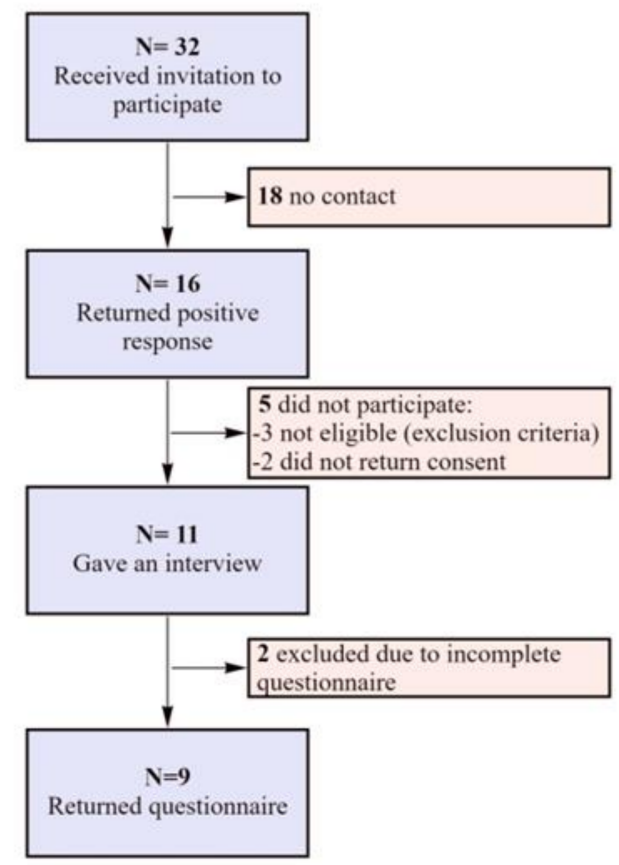

Figure 1. Flowchart of participant enrollment.

Table 1. Study respondents' sociodemographic and health data.

\begin{tabular}{|c|c|c|c|c|c|c|c|}
\hline Patient & Age & Continent & Marital Status & $\begin{array}{c}\text { Years Since } \\
\text { Injury }\end{array}$ & SCI Level & $\begin{array}{c}\text { Discipline before } \\
\text { SCI }\end{array}$ & Sport after SCI \\
\hline P1 & 41 & Europe & Divorced & 14 & $\mathrm{C} 3 / 4$ & BMX dirt jumps & No \\
\hline P2 & 24 & Europe & Informal relationship & 6 & Th11/12 & Karate & $\begin{array}{l}\text { Wheelchair } \\
\text { dancing }\end{array}$ \\
\hline $\begin{array}{l}\text { P3 } \\
\text { P4 } \\
\text { P5 } \\
\text { P6 }\end{array}$ & $\begin{array}{l}29 \\
55 \\
31 \\
37\end{array}$ & $\begin{array}{c}\text { Europe } \\
\text { North America } \\
\text { Europe } \\
\text { Europe }\end{array}$ & $\begin{array}{c}\text { Single } \\
\text { Married } \\
\text { Informal relationship } \\
\text { Informal relationship }\end{array}$ & $\begin{array}{c}5 \\
4 \\
15 \\
16\end{array}$ & $\begin{array}{l}\text { C6/7 } \\
\text { C6/7 } \\
\text { Th6 } \\
\text { C4/5 }\end{array}$ & $\begin{array}{c}\text { Ski jumping } \\
\text { Mountain bike racing } \\
\text { Motocross } \\
\text { Rugby }\end{array}$ & $\begin{array}{c}\text { Rugby, skiing } \\
\text { No } \\
\text { Car racing } \\
\text { No }\end{array}$ \\
\hline P7 & 45 & North America & Married & 14 & Th12/L1 & Mountain biking & $\begin{array}{l}\text { Wheelchair } \\
\text { basketball }\end{array}$ \\
\hline $\begin{array}{l}\text { P8 } \\
\text { P9 }\end{array}$ & $\begin{array}{l}40 \\
47\end{array}$ & $\begin{array}{l}\text { Europe } \\
\text { Europe }\end{array}$ & $\begin{array}{l}\text { Informal relationship } \\
\text { Single }\end{array}$ & $\begin{array}{l}17 \\
15\end{array}$ & $\begin{array}{l}\text { Th11 } \\
\text { L1/2 }\end{array}$ & $\begin{array}{l}\text { Judo } \\
\text { Speedway }\end{array}$ & $\begin{array}{c}\text { Canoe } \\
\text { Hand cycling }\end{array}$ \\
\hline
\end{tabular}

\subsection{Quality of Life and Self-Efficacy}

Table 2 shows the participants' scores on each scale and its components, along with the mean and standard deviation. For the overall quality-of-life question, the mean value was $\mathrm{Q} 1=4.11$, which is a positive rating. Only two participants (P1, P4) rated their quality of life negatively; these two individuals were also not satisfied with their health status. In a comment on the WHOQoL-BREF scale, participant P1 indicated that he had been in poor health for the past 4 weeks, which is the period referred to by the scale questions. Despite the severe pain experienced by participant P1 daily, according to his response in Q5, this pain does not prevent him from doing what he needs to do. The lowest scores in all domains of quality of life as well as the GSES scale were obtained by participant $\mathrm{P} 4$, who indicated in his interview that he already had a depressive personality before the accident, which worsened after the SCI. It is puzzling that participant P8 had one of the lowest scores on the self-efficacy scale, despite his high sporting achievements after the accident-that is, winning a gold medal at the Paralympics and silver twice at the world championships. At the same time, participant P9, who is a three-time Paralympic gold medalist and a five-time world champion in hand-cycling, had the highest GSES score. There were no statistically significant differences in the WHOQoL-BREF and GSES scale scores among post-injury athletes $(n=6)$ and non-athletes $(n=3)$, so no such division was used in the statistical analysis. 
Table 2. WHOQoL-BREF and GSES scores.

\begin{tabular}{cccccccccccc}
\hline \multicolumn{1}{c}{ Scale } & & P1 & P2 & P3 & P4 & P5 & P6 & P7 & P8 & P9 & Mean \pm SD \\
\hline & Q1 & $3^{*}$ & 4 & 4 & $2^{*}$ & 5 & 5 & 5 & 4 & 5 & $4.11 \pm 1.05$ \\
& Q2 & $1^{*}$ & 4 & 5 & $2^{*}$ & 5 & 3 & 5 & 4 & 5 & $3.78 \pm 1.48$ \\
WHOQOL & D1 & 14 & 18 & $11^{*}$ & $11^{*}$ & 20 & 15 & 19 & 16 & 14 & $15.33 \pm 3.24$ \\
& D2 & $13^{*}$ & 19 & 15 & $7^{*}$ & 17 & 15 & 19 & 15 & 20 & $15.56 \pm 3.97$ \\
& D3 & $13 *$ & 20 & $12^{*}$ & $9^{*}$ & 17 & 17 & 19 & 16 & 20 & $15.89 \pm 3.83$ \\
& D4 & 16 & 17 & 16 & 13 & 20 & 17 & 20 & 13 & 20 & $16.89 \pm 2.75$ \\
\hline GSES & 31 & 34 & 33 & $20^{*}$ & 36 & 33 & 34 & $28^{*}$ & 39 & $32.22 \pm 4.89$ \\
Pain & $7^{*}$ & 3 & $7^{*}$ & $6^{*}$ & 0 & 0 & 1 & 3 & $7^{*}$ & $3.77 \pm 3.03$ \\
\hline
\end{tabular}

* Lowest scale scores and highest level of pain.

Spearman's correlation showed that self-efficacy was related to the general perception of quality of life (Q1) and satisfaction with one's physical health (Q2), as well as psychological resources (D2) and environmental support (D4) (Table 3). In contrast, it is interesting that neither pain nor time since the accident was significant for the QoL or GSES measures. In the context of the specificity of the group after spinal cord injury, the lack of correlation between self-efficacy and self-assessment of physical health (D1) and social relationships (D3) is noteworthy.

Table 3. Spearman's rank-order correlation.

\begin{tabular}{lccccccc}
\hline & Q1 & Q2 & D1 & D2 & D3 & D4 & GSES \\
\hline GSES & $0.786844^{*}$ & $0.736262^{*}$ & 0.309322 & $0.781181^{*}$ & 0.593220 & $0.870334^{*}$ & \\
Pain & -0.545816 & -0.112136 & -0.435410 & 0.043669 & 0.094842 & -0.233482 & -0.181061 \\
Years & & & & & & & \\
since & -0.124132 & -0.209849 & -0.235302 & -0.110663 & -0.058826 & -0.042938 & -0.218495 \\
injury & & & & & & & \\
\hline
\end{tabular}

* Correlation coefficients that are significant $(p<0.05)$.

\section{Discussion}

In this study, we presented the quality of life and self-efficacy of nine top athletes after SCIs, and at the same time attempted to search for the correlations between these measures. The relationship between quality of life and self-efficacy has been widely studied [13,21-23,27]. However, to the best of our knowledge, this study is the first to assess this aspect among elite athletes. We hypothesized that outstanding athletes, despite spinal cord injury, possess special intrinsic personal attributes that translate to good quality of life and high self-efficacy. This hypothesis is line with the findings of Kopp's (2018) meta-analytical investigation, which showed that high emotional intelligence correlates with high athletic achievement [34-36].

According to previous studies, individuals with SCIs had poorer quality of life and lower self-efficacy compared to the general population $[12,18,23,27]$. However, in other research among athletes, higher quality of life was declared by people with spinal cord injuries participating in sport more often and at a higher level [37]. In a study by Ciampolini (2017), who evaluated the quality of life among Brazilian wheelchair tennis athletes, higher perceptions in the physical domain and total QoL were found among an elite group [38]. Despite the traumatic accident and the necessity of a complete change of lifestyle-two subjects had to give up sport completely, and six had to give up their previous sport-the participants evaluated their quality of life positively.

Undoubtedly, spinal cord injury affects physical health and, thus, influences the low scores in this domain. Participant P1 gave the lowest score in the overall assessment of his health due to the presence of decubitus ulcers and the need to remain in bed during the study period, which also influenced some of the lowest scores in the psychological domain and the deterioration of social relationships. The remaining participants (except for P3 and P4), despite para- and tetraplegia, were generally satisfied with their health. There was also no correlation found between the amount of core damage and the results of the 
WHOQoL-BREF and GSES scales. This confirms the findings of previous studies, where it was shown that health satisfaction is influenced more by secondary health issues than by primary accident-related damage $[15,21,23,27]$.

According to previous studies, pain has a strong impact on quality of life [1,2,39]. However, in our study, there was no correlation between pain and QoL. Furthermore, participant $\mathrm{P} 9$, with one of the highest scores for pain experienced daily, also had the highest scores on the quality of life scale.

Previous studies have indicated that major problems after SCIs include social disadvantages arising from the impairment and social participation restrictions $[8,13]$. In Unver's (2015) study of wrestlers at different athletic levels, the national-level wrestlers achieved the highest scores in the social domain [40]; the author explains this result by pointing to the contacts national wrestlers have with athletes from different countries through competitions. Similar findings were observed among athletes participating in the study presented here who, because of their high sporting achievements before the accident, could count on the support of the sporting community, fans, and participation in sporting life in both active (sport for the disabled) and passive (motivational speeches, role of coach) form, making them active in the social domain.

P4 had the lowest scores on the QoL scale, self-efficacy assessment with high levels of pain, and the shortest time since the accident. Depressive tendencies were also noted in the interview, as indicated by the respondent himself. In studies by Kennedy et al., (2008) and Diemen et al., (2017), higher scores for depression and anxiety were correlated with lower scores for perceived resourcefulness and self-efficacy [41,42]. According to Middleton (2007), people with negative thinking may be at higher risk of negative medical outcomes, such as pain [13]. Furthermore, patients who reported their pre-injury personality as having been depressive presented less adjustment to their SCI [23,43].

Studies by Sklett et al., (2018) and Treasure (1996) indicate that self-efficacy is associated with performance in ski jumping and among wrestlers, respectively [44,45]. Despite spinal cord injury, our subjects' GSES scores were higher compared to previous studies involving SCI patients [33].

Prior research has produced data to suggest that S-E is associated with the perception of quality of life, general health quality, and WHOQoL domains, as also indicated by the results of our study $[13,21,22]$. Unlike previous studies, no correlation of S-E with the level of pain was observed, which may be related to the characteristics of the study group. The findings of previous studies suggest that sports with long durations of physically intense activity are associated with increased ability to tolerate pain [46]. The participants in this study indicated sport as having played a significant role in shaping their personalities.

The participants were characterized by a long time having passed since their accidents ( $>4$ years). This may be the reason for the lack of correlation between the GSES and psychological or social domains, as subjects had already passed various linear stages of adjustment, leading to an optimal adjustment to SCI [47]. Only one participant (P4) -with the shortest time since the accident (4 years) - appeared to have yet to finally accept his new reality and express a desire to grow following the trauma, as is also indicated by his results. According to Catalano (2011), environmental factors are a protective element, increasing the chances of adaptive adjustment [10]. This is consistent with our results, where the correlation of the GSES scores with the environmental domain of the WHOQoL scale was shown. According to Hampton's studies $(2000,2001)$, regardless of social support, individuals with higher S-E levels were found to be more satisfied with their lives than those with lower S-E levels [21,22].

Previous studies on self-efficacy show that QoL among individuals with SCIs is more dependent on the attitude a person adopts than on permanent factors related to their disability - that is, the level or completeness of their impairment $[15,21,23,27]$. Such findings offer hope for improving the QoL of persons with SCIs, despite the lack of impact on the disability itself. 
The original intention of this study was to collect a group of subjects from all over the world so that the results would be global in scope, regardless of nationality or healthcare system. Due to the specific group of subjects and the small number of individuals meeting the inclusion criteria, we were unable to fully achieve this goal, which can be seen as a limitation. However, reaching out to nine outstanding athletes with spinal cord injuries, coming from four countries located on two continents, gives some insight into the situation under study. It also seems that increasing the number of participants would allow us to observe possible differences between athletes who participate in sports after their injury and those who do not continue a professional sports career.

\section{Conclusions}

The results of this study indicate that S-E is significantly correlated with the general perception of QoL, health, and psychological resources, as well as environmental support. Sport positively influences the wellbeing of individuals after SCIs regardless of whether it was played before and currently is not, as it encourages the development of traits that allow for better adjustment. Involvement in an environment that was important to the injured person before the accident-in either a passive (in the absence of functional capabilities) or active form-promotes greater self-efficacy and good QoL, regardless of the time elapsed since the accident, and despite high levels of pain or secondary health issues.

The results of this study offer a suggestion for clinical professionals to motivate patients to undertake active rehabilitation by showing examples of outstanding athletes who, despite the shock they experienced after their injuries, were able to adapt to their new situation, resulting in a good quality of life. We also believe that intervention programs should be considered that support S-E, which is an important factor that is subject to improvement.

Supplementary Materials: The following are available online at https:/ / www.mdpi.com/article/10.3 390/ijerph182010866/s1, Consent of participation.

Author Contributions: Conceptualization, A.G. and G.Z.; methodology, A.G., A.Z. and G.Z.; software, A.G., K.K. and M.L.; validation, A.G., M.L. and G.Z.; formal analysis, A.G., A.Z. and K.K.; investigation, A.G., G.Z. and A.Z.; resources, A.G. and A.Z.; data curation, A.G. and M.L.; writingoriginal draft preparation, A.G., G.Z. and M.L.; writing-review and editing, A.G., G.Z. and K.K.; visualization, A.Z. and K.K.; supervision, G.Z. and A.Z.; project administration, A.G. and K.K. All authors have read and agreed to the published version of the manuscript.

Funding: This research received no external funding.

Institutional Review Board Statement: This study was conducted in accordance with the guidelines of the Declaration of Helsinki and approved by the Senate Research Ethics Committee of the University School of Physical Education in Wroclaw, Poland (corresponding ethical approval code: 37/2018, art.27, Dz.U.1997, poz.553, 10 December 2018).

Informed Consent Statement: Informed consent was obtained from all subjects involved in the study.

Data Availability Statement: The datasets used and/or analyzed during this study are available from the corresponding author upon reasonable request.

Acknowledgments: We would like to express our great gratitude to the participants and our respect and appreciation for their unbroken attitudes.

Conflicts of Interest: The authors declare no conflict of interest.

\section{References}

1. Andresen, S.R.; Biering-Sørensen, F.; Hagen, E.M.; Nielsen, J.F.; Bach, F.; Finnerup, N. Pain, spasticity and quality of life in individuals with traumatic spinal cord injury in Denmark. Spinal Cord 2016, 54, 973-979. [CrossRef] [PubMed]

2. Hadjipavlou, G.; Cortese, A.M.; Ramaswamy, B. Spinal cord injury and chronic pain. BJA Educ. 2016, 16, 264-268. [CrossRef]

3. Barker, R.N.; Kendall, M.D.; Amsters, D.; Pershouse, K.J.; Haines, T.; Kuipers, P. The relationship between quality of life and disability across the lifespan for people with spinal cord injury. Spinal Cord 2008, 47, 149-155. [CrossRef] [PubMed] 
4. Liem, N.R.; McColl, M.A.; King, W.; Smith, K.M. Aging with a spinal cord injury: Factors associated with the need for more help with activities of daily living. Arch. Phys. Med. Rehabil. 2004, 85, 1567-1577. [CrossRef] [PubMed]

5. Spong, J.; Graco, M.; Brown, D.J.; Schembri, R.; Berlowitz, D.J. Subjective sleep disturbances and quality of life in chronic tetraplegia. Spinal Cord 2015, 53, 636-640. [CrossRef]

6. Beauregard, L.; Guindon, A.; Noreau, L.; Lefebvre, H.; Boucher, N. Community Needs of People Living with Spinal Cord Injury and Their Family. Top. Spinal Cord Inj. Rehabil. 2012, 18, 122-125. [CrossRef] [PubMed]

7. Hammell, K.W. Exploring quality of life following high spinal cord injury: A review and critique. Spinal Cord 2004, 42, 491-502. [CrossRef]

8. Kreuter, M.; Siösteen, A.; Erkholm, B.; Byström, U.; Brown, D.J. Health and quality of life of persons with spinal cord lesion in Australia and Sweden. Spinal Cord 2004, 43, 123-129. [CrossRef]

9. Palimaru, A.; Cunningham, W.E.; Dillistone, M.; Vargas-Bustamante, A.; Liu, H.; Hays, R.D. A comparison of perceptions of quality of life among adults with spinal cord injury in the United States versus the United Kingdom. Qual. Life Res. 2017, 26, 3143-3155. [CrossRef]

10. Catalano, D.; Chan, F.; Wilson, L.; Chiu, C.-Y.; Muller, V.R. The buffering effect of resilience on depression among individuals with spinal cord injury: A structural equation model. Rehabil. Psychol. 2011, 56, 200-211. [CrossRef]

11. Krause, J.S.; Cao, Y.; DiPiro, N. Psychological factors and risk of mortality after spinal cord injury. J. Spinal Cord Med. 2019, 43, 667-675. [CrossRef] [PubMed]

12. Post, M.W.M.; Van Leeuwen, C.M.C. Psychosocial issues in spinal cord injury: A review. Spinal Cord 2012, 50, 382-389. [CrossRef]

13. Middleton, J.; Tran, Y.; Craig, A. Relationship Between Quality of Life and Self-Efficacy in Persons with Spinal Cord Injuries. Arch. Phys. Med. Rehabil. 2007, 88, 1643-1648. [CrossRef]

14. Haran, M.J.; Lee, B.; King, M.T.; Marial, O.; Stockler, M.R. Health Status Rated with the Medical Outcomes Study 36-Item Short-Form Health Survey After Spinal Cord Injury. Arch. Phys. Med. Rehabil. 2005, 86, 2290-2295. [CrossRef]

15. Deroon-Cassini, T.A.; Aubin, E.D.S.; Valvano, A.; Hastings, J.; Horn, P. Psychological well-being after spinal cord injury: Perception of loss and meaning making. Rehabil. Psychol. 2009, 54, 306-314. [CrossRef] [PubMed]

16. Goraczko, A.; Zurek, G.; Lachowicz, M.; Zurek, A. Purpose in Life of Elite Athletes after Spinal Cord Injury. Int. J. Environ. Res. Public Health 2021, 18, 5563. [CrossRef]

17. Craig, A.; Perry, K.N.; Guest, R.; Tran, Y.; Middleton, J. Adjustment following chronic spinal cord injury: Determining factors that contribute to social participation. Br. J. Health Psychol. 2015, 20, 807-823. [CrossRef] [PubMed]

18. Craig, A.; Tran, Y.; Middleton, J. Theory of adjustment following severe neurological injury: Evidence supporting the Spinal Cord Injury Adjustment Model. In Horizons in Neuroscience Research; Costa, A., Villalba, E., Eds.; Nova Science Publishers: New York, NY, USA, 2017; Volume 29, pp. 117-139.

19. Sherer, M.; Adams, C. The Self-Efficacy Scale: Construction and validation. Psychol. Rep. 1982, 51, 663-671. [CrossRef]

20. Badenhorst, M.; Brown, J.; Lambert, M.I.; Van Mechelen, W.; Verhagen, E. Quality of life among individuals with rugby-related spinal cord injuries in South Africa: A descriptive cross-sectional study. BMJ Open 2018, 8, e020890. [CrossRef]

21. Hampton, N.Z. Disability status, perceived health, social support, self-efficacy, and quality of life among people with spinal cord injury in the People's Republic of China. Int. J. Rehabil. Res. 2001, 24, 69-71. [CrossRef]

22. Hampton, N.Z. Self-Efficacy and Quality of Life in People with Spinal Cord Injuries in China. Rehabil. Couns. Bull. 2000, 43, 66-74. [CrossRef]

23. Peter, C.; Müller, R.; Cieza, A.; Geyh, S. Psychological resources in spinal cord injury: A systematic literature review. Spinal Cord 2011, 50, 188-201. [CrossRef]

24. Ackery, A.; Hagel, B.E.; Provvidenza, C.; Tator, C.H. An international review of head and spinal cord injuries in alpine skiing and snowboarding. Inj. Prev. 2007, 13, 368-375. [CrossRef]

25. Chan, C.W.; Eng, J.J.; Tator, C.H.; Krassioukov, A. the Spinal Cord Injury Research Evidence Team Epidemiology of sport-related spinal cord injuries: A systematic review. J. Spinal Cord Med. 2016, 39, 255-264. [CrossRef]

26. Patel, S.A.; Vaccaro, A.R.; Rihn, J.A. Epidemiology of Spinal Injuries in Sports. Oper. Tech. Sports Med. 2013, 21, 146-151. [CrossRef]

27. Carrard, V.; Kunz, S.; Peter, C. Mental health, quality of life, self-efficacy, and social support of individuals living with spinal cord injury in Switzerland compared to that of the general population. Spinal Cord 2020, 59, 1-12. [CrossRef]

28. Atkinson, P.A.; Martin, C.R.; Rankin, J. Resilience revisited. J. Psychiatr. Ment. Health Nurs. 2009, 16, 137-145. [CrossRef] [PubMed]

29. Jang, Y.; Hsieh, C.-L.; Wang, Y.-H.; Wu, Y.-H. A validity study of the WHOQOL-BREF assessment in persons with traumatic spinal cord injury. Arch. Phys. Med. Rehabil. 2004, 85, 1890-1895. [CrossRef]

30. Lin, M.-R.; Hwang, H.-F.; Chen, C.-Y.; Chiu, W.-T. Comparisons of the Brief Form of the World Health Organization Quality of Life and Short Form-36 for Persons with Spinal Cord Injuries. Am. J. Phys. Med. Rehabil. 2007, 86, 104-113. [CrossRef]

31. The Whoqol Group. The World Health Organization quality of life assessment (WHOQOL): Development and general psychometric properties. Soc. Sci. Med. 1998, 46, 1569-1585. [CrossRef]

32. World Health Organization. Measuring Quality of Life, Program on Mental Health; World Health Organization: Geneva, Switzerland, 1997.

33. Peter, C.; Cieza, A.; Geyh, S. Rasch analysis of the General Self-Efficacy Scale in spinal cord injury. J. Health Psychol. 2014, 19, 544-555. [CrossRef] 
34. Kopp, A.; Jekauc, D. The Influence of Emotional Intelligence on Performance in Competitive Sports: A Meta-Analytical Investigation. Sports 2018, 6, 175. [CrossRef]

35. Birwatkar, V.P. Emotional Intelligence: The Invisible Phenomenon in Sports. Euro. J. Sports Exerc. Sci. 2014, 3, 19-31.

36. Castro-Sanchez, M.; Chacon-Cuberos, R.; Zurita-Ortega, F.; Puertas-Molero, P.; Sanchez-Zafra, M.; Ramirez-Granizo, I. Emo-tional intelligence and motivation in athletes of different modalities. J. Hum. Sport Exerc. 2018, 13, 162-177.

37. Chatzilelecas, E.; Filipović, B.; Petrinović, L. Differences in Quality of Life According to the Level of Ohysical Activity between Two Groups of Basketball Players in the Wheelchairs. Sportlogia 2015, 11, 11-17. [CrossRef]

38. Ciampolini, V.; Columna, L.; Lapolli, B.; Iha, T.; Grosso, E.C.; Silva, D.A.S.; Galatti, L.R. Quality of life of Brazilian wheelchair tennis athletes across competitive and elite levels. Mot. Rev. Educ. Física 2017, 23, e101703. [CrossRef]

39. van Koppenhagen, C.F.; Post, M.W.; van der Woude, L.H.; de Groot, S.; de Witte, L.P.; van Asbeck, F.W.; Heuvel, W.V.D.; Lindeman, E. Recovery of Life Satisfaction in Persons with Spinal Cord Injury During Inpatient Rehabilitation. Am. J. Phys. Med. Rehabil. 2009, 88, 887-895. [CrossRef]

40. Unver, S.; Atan, T.; Cavusoglu, G.; Erim, V.; Yamak, B. A comparison of levels of quality of life, depression and loneliness among athletes with different levels of training. Educ. Res. Rev. 2015, 10, 130-134. [CrossRef]

41. Kennedy, P.; Taylor, N.; Hindson, L. A pilot investigation of a psychosocial activity coursefor people with spinal cord injuries. Psychol. Health Med. 2006, 11, 91-99. [CrossRef] [PubMed]

42. van Diemen, T.; Crul, T.; van Nes, I.; Geertzen, J.H.; Post, M.W. Associations Between Self-Efficacy and Secondary Health Conditions in People Living with Spinal Cord Injury: A Systematic Review and Meta-Analysis. Arch. Phys. Med. Rehabil. 2017, 98, 2566-2577. [CrossRef]

43. Krause, J.S. Personality and Traumatic Spinal Cord Injury: Relationship to Participation in Productive Activities. J. Appl. Rehabil. Couns. 1997, 28, 15-20. [CrossRef]

44. Sklett, V.H.; Lorås, H.W.; Sigmundsson, H. Self-Efficacy, Flow, Affect, Worry and Performance in Elite World Cup Ski Jumping. Front. Psychol. 2018, 9, 1215. [CrossRef] [PubMed]

45. Treasure, D.C.; Monson, J.; Lox, C.L. Relationship between Self-Efficacy, Wrestling Performance, and Affect Prior to Competition. Sport Psychol. 1996, 10, 73-83. [CrossRef]

46. Pattersen, S.D.; Alsaksen, P.; Pettersen, S.A. Pain Processing in Elite and High-Level Athletes Compared to Non-athletes. Front. Psychol. 2020, 11, 1908. [CrossRef] [PubMed]

47. Kennedy, P. Coping effectively with spinal cord injuries. In Psychological Dynamics Associated with Spinal Cord Injuries Rehabilitation: New Directions and Best Evidence; Tran, C., Tran, Y., Eds.; Nova Science Publishers: New York, NY, USA, 2008 ; pp. 55-70. 